\title{
Food Insecurity and it's Predictors Among Vulnerable Children
}

\author{
Abok Ibrahim Ishaya*, Yilgwan Christopher Sabo and John Collins
}

\author{
Department of Paediatrics, Jos University Teaching Hospital, Nigeria
}

\begin{abstract}
Background: To determine the prevalence of food insecurity and some socio demographic predictors of food insecurity among Vulnerable Children (VC) in Jos, North- central Nigeria

Methods: A cross-sectional comparative study involving 202 VC selected using multi-stage sampling technique across two orphanages and three communities located in sub-urban areas in Jos East, Jos North and Jos South Local Government Area was carried out. A VC was defined as a child who has loss mother, father or both or children who reside with chronically ill parents or reside in institution during the study. Only VC greater than five years but less than 18 years were enrolled.

Food security was measured using four questions that were adapted from existing questionnaires. Food insecurity was defined and graded has mild, moderate or high if there was an affirmative response to any one, two or three of four questions.

Data generated were analyzed using EPI Info version 3.65 software. The independent variables orphan status, age, gender, place of residence, child level of education, child work, were compared with the dependent variables of food insecurity using bivariate and multivariate analysis. In all statistical test $p<0.05$ was considered statistically significant.

Results: Of the 202 VC analyzed $38.6 \%(78)$ were girls and $61.4 \%(124)$ were boys with a mean age of $12.7 \pm 2.6$ years. One hundred and two (50.5\%) were IVC while 100(49.5\%) were HVC. The VC were mostly orphans (83.2\% [168]) while $16.8 \%(34)$ were non orphans. All children were enrolled into school, 137 were in primary school, while the rest were in secondary school. Majority of the HVC were cared for by their mother $(24.8 \% 50[\mathrm{VC}])$, father (1.9\% [4]), uncles $(8.4 \%$ [17]), aunts (10\% [5.0]), grandparents (5.4\% [11]), and non relatives (8\% [4.0]).

The overall prevalence of food insecurity was $48.5 \%$. Of the 98 Food insecure VC $65 \%$ were HVC compared to $35 \%$ observed among IVC $(\mathrm{p}<0.05) ; 69.6 \%$ were children older than 12 years compared to $30.4 \%$ obsereved in VC who were $<12$ years.

The odds of food insecurity was 2.1 times in older VC aged 13-18 years $(\mathrm{Cl}=1.1-3.9)$. VC attending Secondary School were 1.9 time likely to be food insecure compared to those in primary school $(\mathrm{Cl}=1.1-3.5)$. Similarly, HVC were 3.6 times more likely to be food insecure compared to IVC. $(\mathrm{Cl}=1.9-6.9)$. VC who worked to earn money had a 2.8 times odd to be food insecure $(\mathrm{Cl}=1.2-6.24)$. Paternal orphans were 2.4 times more likely to be food insecure $(\mathrm{Cl}=1.0-6.5)$ compared to other group of VC. Being a maternal orphan, a double orphan or non orphan VC does not predict food insecurity. Sexual experience was also not a predictor of food insecurity.

Conclusion: The implication of hunger, in an adolescent child who considered himself/herself overworked is enormous on child physical, emotional and social development. This might lead to more children living their homes to seek shelter in orphanages were the food security status even though not perfect is better than the household. This can be prevented if Household VC are actively identified and their families supported with programs that can make them food secure.
\end{abstract}

Keywords: Vulnerable children, Food Insecurity, Nutritional status, socio-demographic.

\section{INTRODUCTION}

Food insecurity is said to be present when there is limited or uncertain availability or access to nutritionally adequate, culturally acceptable and safe foods [1]. It is a social health problem with global dimensions and an important factor in achieving child health related millennium development in sub-Saharan Africa, Nigeria inclusive [2, 3].

The prevalence of food insecurity vary throughout the world, ranging from approximately $17 \%$ in Asia and the Pacific to $33 \%$ in most part of Africa [4].

Household food insecurity studies in Nigeria have shown a prevalence of $30-70 \%$ [5-7]. This may

*Address correspondence to this author at the Department of Paediatrics, Jos University Teaching Hospital, Nigeria; Tel: +2345379692;

E-mail: abokii@yahoo.com represent a small proportion of the problem especially with the dearth of studies amongst orphans and other vulnerable children.

Focus on Vulnerable children was intensified at the onset of the HIV/AIDS (Human Immune deficiency Virus/Aquired Immuno Deficiency Syndrome) epidemic. Children who lost either one or both parents due to HIV/AIDS were initially referred to as AIDS orphans. a term later considered to be stigmatizing. This term evolved over time to Orphans and vulnerable children to the current usage of vulnerable children $[8,9]$.

The definitions of a VC may vary from country to country and even within the same country. Based on Nigerian national Policy a child is vulnerable if he/she lacks adequate access to educational, health and other social support, has a chronically ill parent, lives in a house with terminally or chronically ill parent(s) or 
caregiver(s), lives with old/frail grandparents(s) or caregiver(s). A child who lives outside of family care for example lives with extended family, in an institution, or on the street. A child who is infected with HIV/AIDS [8]. The VC can be describe as a child who lacks support/protection and is far from attaining his/her right as stated in the child's right acts. This places every VC at risk of lacking basic needs such as health care, food, shelter, clothing, love and other social services [11, 12].

The interaction between poverty, poor health and low human developmental indices as seen in Nigeria posses enormous challenges, especially on the care and support given to every VC irrespective of place of residence. This might reflect first and foremost on the accessibility and availability of adequate quality food to VC $[9,13,14]$.

If food insecure, a child might develop disorders of cognitive and psychomotor development, in addition to nutritional and other health related disorder which can have dire consequences on the child present and future quality of life and wellbeing [2, 15].

If VC are to attain maximum growth and developmental potential the need for them to access sufficient and quality food is crucial. It is therefore necessary to study the proportion of VC who are food insecure and find out the associated factors.

\section{METHODS}

The study was carried out in Jos North, South and East Local Governments Areas (LGA) in Plateau State. The three LGA's are all highland areas with rocky terrain and similar climatic condition and have similar ethnic groups [16].

The study subjects were vulnerable children living in the study area during the survey, who were resident in either a household or an orphanage. A child is included into the study if he or she is less than 18 years but greater than 5 years and is either an orphan (a child who has lost either one or both of his/her parents) or Lives in a household where at least one adult was seriously ill for at least 3 months in the previous 12 months or Children who are living in orphanages

This study was a cross -sectional comparative study of the selected communities and orphanages.

The sample size was determine using the formula for comparison of proportion and assumed prevalence of food-insecurity of $50 \%$ with 0.05 as the margin of error [17].
A multistage sampling technique was used. Two orphanages were sampled from the list of 3 orphanages. One of the orphanages was excluded because all inmates were below the age of 5years. The number of VC was sampled from the remaining two orphanages in proportion to number of VC who were eligible for inclusion. Therefore $99 \mathrm{VC}$ were sampled from Gidan bege, while 3 were sampled from OLA orphanage.

Three Non-Governmental Organization caring for VC were used as contact to households with VC in three sub- urban communities namely Tanchol, Sabon Fobur and Mado village located in Jos south, Jos- east and Jos- north LGA respectively. In each of these selected community $34 \mathrm{VC}$ were sampled.

\section{Data Collection}

Data collection was done using a pretested interviewer administered questionnaire. The information generated included demographic and social variables. The height and weight of each child was assessed using a Healthline ${ }^{\circledR}$ weighing scale and stadiometer using standard protocols.

Food security was measured using four questions that were adapted from existing questionnaires [18, 19].

1. If the child goes to school without food

2. If the child has experience going to bed without food

3. If the child experiences food shortages

4. If the child has skipped a meal because there was no enough food to eat

Food insecurity was defined and graded has mild, moderate or high if there is an affirmative response to any one, two or three of the four questions respectively.

Anthropometric assessment and other data generated were analyzed using EPI Info version 3.65 software. The independent variables orphan status, age, gender, place of residence child level of education, sexual experience, child work were compared with the dependent variables of food insecurity using bivariate and multivariate analysis. In all statistical test $p<0.05$ was considered statistically significant. 


\section{RESULTS}

Out of the 202 VC analyzed $38.6 \%(78)$ were girls and $61.4 \%(124)$ were boys giving a male/ female ratio of 1: 0.6 . The mean age of the studied population was $12.7 \pm 2.6$ years with an age range of $6-17$ years. Male VC had a higher mean age of $12.8 \pm 2.6$ years while females had a mean age of $12.5 \pm 2.6$ years. However, this difference was not statistically significant $(p>0.05)$.

Of the 202 VC $50.5 \%(102)$ were IVC while $49.5 \%$ were HVC. The VC were mostly orphans (83.2\% [168]) while $16.8 \%(34)$ were non orphans. One hundred and thirty seven children attended primary school while the rest were in secondary school. The caregivers of all institutionalized children were the orphanage staff while majority of the HVC were cared by mother $(24.8 \%$ $50[\mathrm{VC}])$, Uncles (8.4\% [17]), Aunt (10\% [5.0]), Grandparents (5.4\% [11]), Non relatives (8\% [4.0]) and surviving biologic father (1.9\% [4]) Table 1.
Food Insecurity and Socio Demographic Variables

The prevalence of food insecurity in the studied subject was $48.5 \%$. Of the 202 VC who were studied $38(11.4 \% \%)$ had mild food insecurity, $23(11.4 \%)$ had moderate food insecurity and $37(18.3 \%)$ had severe food insecure. This is shown on Figure 1. Food insecurity was significantly associated with place of residence, age group and levels of education. There were no statistical association in food insecurity status between orphaned vulnerable children and non orphaned vulnerable children. Food insecurity was also not associated with gender see Table 1.

In the multivariate analysis in Table 2 the odds of food insecurity was 2.1 times in older VC aged 13-18 years $(\mathrm{Cl}=1.1-3.9)$. $\mathrm{VC}$ attending Secondary School were 1.9 time likely to be food insecure compared to those in primary school $(\mathrm{Cl}=1.1-3.5)$. Similarly, HVC were 3.6 times more likely to be food insecure compared to IVC $(\mathrm{Cl}=1.9-6.9)$. VC who worked to earn

Table 1: Socio-Demographic Characteristics of the Sample, Stratified by Household Food Insecurity Status

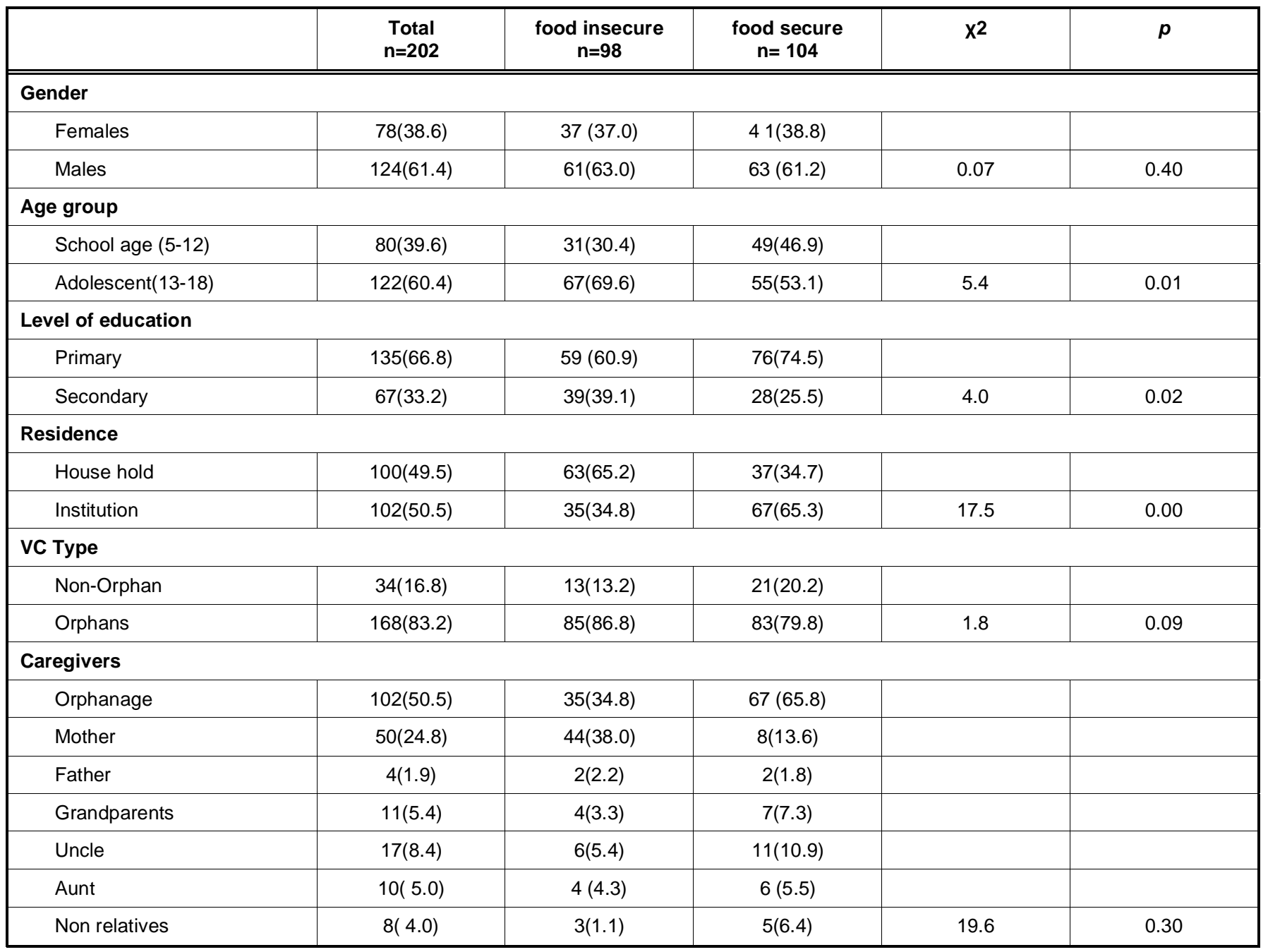




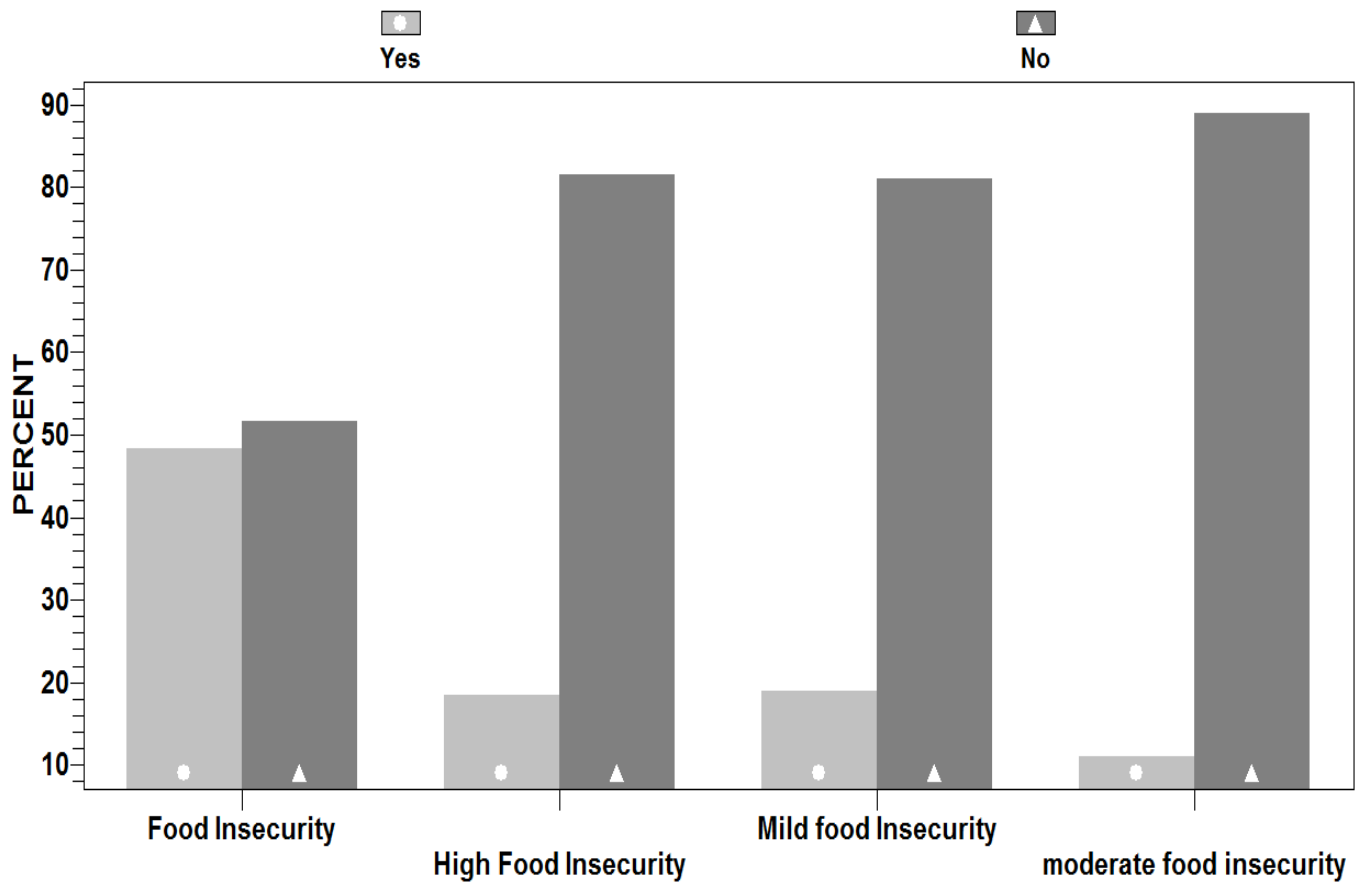

Figure 1: Bar Chart showing distribution of Mild, moderate, high and Overall food insecurity in VC.

Table 2: Association Between Food Insecurity and Social, Demographic Variables Using Multivariate Logistic Regression ( $\mathrm{N}=202)$

\begin{tabular}{|c|c|c|c|}
\hline Parameter & OR & Cl value & 0.02 \\
\hline \hline Age group(13-18/<13) & 2.10 & $1.10-3.90$ & 0.045 \\
\hline Education (secondary/Primary) & 1.9 & $1.1-3.5$ & 0.54 \\
\hline Gender(Male/Female) & 2.10 & $0.6-2.3$ & 0.00 \\
\hline HVC (Yes/No) & 3.5 & $1.9-6.4$ & 0.86 \\
\hline Double orphan (Yes/No) & 1.10 & $0.42-2.8$ & 0.07 \\
\hline Paternal orphan(Yes/No) & 2.44 & $0.93-6.45$ & 0.15 \\
\hline Maternal orphan(Yes/No) & 1.84 & $0.79-4.28$ & 0.84 \\
\hline Protein( Twice weekly/daily) & 2.59 & $0.20-3.73$ & 0.01 \\
\hline Work for money (Yes/No) & 2.77 & $1.23-6.24$ & 0.87 \\
\hline Sexually experience (Yes/No) & 0.95 & $0.50-1.74$ & 0.046 \\
\hline IIness in last 2 weeks(Yes/No) & 1.86 & $1.1-3.4$ & \\
\hline
\end{tabular}

money had a 2.8times odd to be food insecure $(\mathrm{Cl}=1.2-$ 6.24). Paternal orphans were 2.4 times more likely to be food insecure $(\mathrm{Cl}=1.0-6.5)$ compared to other group of VC. Being a maternal orphan, a double orphan or non orphan VC does not predict food insecurity. Sexual experience was also not a predictor of food insecurity.

\section{Food Insecurity and Nutritional Status}

The mean HAZ score (height for Age $Z$ score) was $-1.7 \pm 1.1$ for the study population. Only one VC had HAZ that was above 2 Standard Deviation. Majority of
VC were stunted as $39.6 \%$ had moderate to severe stunting. Comparatively food insecure VC showed a lower mean of $-1.66 \pm 1.36$ compared to $-1.56 \pm 1.31$ amongst the food secure VC which was not statistically significant $(p>0.05)$.

The mean WAZ score (weight for Age $Z$ score) for the studied population was $0.75 \pm 1.1$. Only $7.4 \%$ of $V C$ had moderate to severe underweight malnutrition. Comparatively food insecure VC showed a lower mean of $-0.9 \pm 1.3$ compared to $-0.8 \pm 0.9$ amongst the food 
secure VC which was not statistically significant $(p>$ 0.05).

\section{DISCUSSION}

This study highlights the prevalence and predictors of food insecurity among VC in Jos, North-central, Nigeria.

The prevalence of food insecurity (48.5\%) observed in this study is within the range of $30-70 \%$ reported in Nigerian households, but higher than $28 \%$ in HIV orphans in Blantyre [5-7, 20]. This finding is not surprising because of the high level of poverty in Nigeria. Our study however, included VC who were enrolled into various support program by Faith Based Organization and Non-Governmental Organization. This support was enjoyed by all IVC and some HVC. The impact of this support might have lowered the overall prevalence of food insecurity and might explain why $65 \%$ of food insecure VC were resident in households. The prevalence of food insecurity among the studied population should be higher [21, 22]. Assessment of food insecurity in a child of the same household as an adult has been shown to be comparatively lower. This difference is thought to occur because of differential distribution of food in favor of children in events of scarcity [19].

Differential vulnerability with paternal orphans having the highest food insecurity status was observed in this study. This finding is similar to that of a previous study in Kenya, and may arise because of the bread winner role played by the father [23]. It may be a reflection of the difficulties faced by women in Africa where men are the sole bread winners and Jobs have some gender inequalities.

It is however surprising that double orphans were less affected by food insecurity. It is difficult to proffer reasons for this observation, however, the fact that majority reside in orphanages may reflect the standard of care and might not be directly related to the lost of their parent. Beside the absences of both parents might draw sympathy and may place them in homes where they are better cared for.

The relationship between food insecurity and child work was observed in this study. This correlation has also been reported in studies in India and among children in Nigeria [24, 25]. The probable reason is that VC are likely to live in houses were the surviving parents or the child's caregiver may need financial supplementation. If this is the case such children will either be send to trade or do menial jobs. It is also possible that this initiative was taken by the VC in order to meet unmet needs especially as it relate to feeding.

The finding of self reported illness among food insecure VC in this current study has also been reported by other authors [26]. However, this result needs to be interpreted with caution as causal relationship cannot be concluded from this study. However, for these children to grow and develop normally and be less prone to ill health specific micronutrient and macro nutrient must be present in food eaten by these children [22].

This study is not without limitation, as all IVC and majority of HVC sampled from Tudun Wada, Fobur had access to support programs. The study design was a cross-sectional and a longitudinal design would have demonstrated the evolution of certain characteristic due to food insecurity.

The placement of VC in household has been shown to be more advantageous compared to Institutional placement. However, this good policy and preference will be threatened if HVC continue to be food insecure. The implication of hunger, in an adolescent child who considered himself/herself overworked is enormous on child physical, emotional and social development. This might lead to more children living their homes to seek shelter in orphanages were the food security status even though not perfect is better than the household. This can be prevented if Household VC are actively identified and their families supported with programs than can make them food secure.

\section{REFERENCES}

[1] Food and Agricultural Organization. Declaration of the World Summit on Food Security. Rome, Italy: Food and Agricultural Organisation 2009. Available @http://www.fao.org/fileadmin/ templates/wsfs/Summit/Docs/Final_Declaration/WSFS09_De claration.pdf

[2] Casey S, Patrick H. Child Health-Related Quality of Life and food insecurity. Arch Pediatr Adolesc Med 2005; 159: 51-56. http://dx.doi.org/10.1001/archpedi.159.1.51

[3] David L, Steve T, Walter M, Pieter van der Zaag BG Implementing the millennium development food security goals - Challenges of the southern African context. Phys Chem Earth Parts A/B/C 2006; 31: 731-37. http://dx.doi.org/10.1016/j.pce.2006.08.002

[4] Kliegman RM, Behrman RE, Jenson HB, Stanton BF. Food Insecurity, Hunger, and Undernutrition IN Nelson Textbook of Pediatrics. 18th ed. Copyright (c) 2007 Saunders, An Imprint of Elsevier 212: 1240-54.

[5] Omuemu VO, Otasowie EM, Onyiriuka U. Prevalence of food insecurity in Egor local government area of Edo State, Nigeria. Ann Afr Med 2012; 11: 139-45. http://dx.doi.org/10.4103/1596-3519.96862 
[6] Ibrahim H, Uba-Eze NR, Oyewole SO, Onuk EG. Food Security among Urban Households: A Case Study of Gwagwalada Area Council of the Federal Capital Territory Abuja, Nigeria. Pak J Nutr 2009; 8: 810-13. http://dx.doi.org/10.3923/pjn.2009.810.813

[7] Sanusi R, Badejo C, Yusuf B. Measuring household food insecurity in selected LGA of Lagos and Ibadan, Nigeria. Pak J Nutr 2006; 5: 62-67. http://dx.doi.org/10.3923/pjn.2006.62.67

[8] Federal Ministry of Women and Social Development Child development department Abuja: National Guidelines and standards of practices on Orphans and Vulnerable Children. Abuja 2007.

[9] United State Agency for International Development. The Highly Vulnerable Children: Causes, Consequences And Action: The U.S. Government Special Advisor for Orphans and Vulnerable Children First Annual Report to Congress, August 2007. Washington 2007.

[10] Office of the United Nations High Commissioner for Human Rights. Convention on the Right of the Child. No date. Retrieved on 24 August, 2009. Available at http://www2. Ohchr.Org/English/Law/Crc.htlm

[11] Godfrey B, Ebunlomo W, Jonathon S, Jill C, Jen B, Bram B. Nigeria Research Situation Analysis on Orphans and Other Vulnerable Children Country Brief 2009.Boston University Center for Global Health and Development. Accessed on 9/9/2010 @:http://www.bu.edu/cghd/files/2009/12/NigeriaResearch-Situation-Analysis-Country-Brief.pdf.

[12] Mangoma J, Chimbari M, Dhlomo E. An Enumeration of Orphans and Analysis of The Problems and Wishes Of Orphans: The Case Of Kariba, Zimbabwe. J Soc Aspects HIV/AIDS 2008; 5: 120-27. http://dx.doi.org/10.1080/17290376.2008.9724910

[13] Ahmed H. Effects of Poverty on Child Health and Paediatric Practice in Nigeria: An Overview. Ann Afr Med 2007; 6: 14256. http://dx.doi.org/10.4103/1596-3519.55705

[14] Nyamukapa C, Foster G, Gregson S. Orphans' Household Circumstances and Access to Education in a Maturing HIV Epidemic in Eastern Zimbabwe. J Soc Develop Afr 2003; 18: 7-32.

[15] Federal Ministry of Women and Social Development. The 2008 Situation Assessment and Analysis on OVC in Nigeria. Federal Ministry of Women and Social Development Abuja, 2009. Retrieved23/9/2009. Available at: www.ovcnigeria. org/Nigeria\%200VC\%20Survey\%20Main\%20Report.
[16] Jos. Wikipedia Available @ en.wikipedia.org/wiki/Jos Last updated 9/7/2010. Accessed 10/10/2010.

[17] WHO. Health Research Methodology. A Guide for Training in Research Method.Regional office of the Western Pacific Manila, 2001. Available@http://www.wpro.who.int/NR/ rdonlyres/3418F27F-60F0-42F9409852F47E09DEF /0/Health_research_edited.pdf

[18] Bickel G, Nord M, Price C, Hamilton W, Cook J. Guide to measuring household food security, revised 2000. Alexandria, VA: U.S. Department of Agriculture, Food and Nutrition Service 2000.

[19] Kuku O, Gundersen G, Garasky S. Differences in food insecurity between adults and children in Zimbabwe. Food Policy 2011; 36: 311-17. http://dx.doi.org/10.1016/j.foodpol.2010.11.029

[20] Rivers J, Mason JB, Rose DD, Eisele TP, Gillespie S, Mahy M, Monasch R. The impact of orphan hood on food security in the high-HIV context of Blantyre. Malawi Food Nutr Bull 2010; 31(3 Suppl): S264-71.

[21] Nyangara F, Thurman TR, Hutchinson P, Obiero W. Effects of Programs Supporting Orphans and Vulnerable Children: Key Findings, Emerging Issues, and Future Directions from Evaluations of Four Projects in Kenya and Tanzania. Measure 2009. http://www.cpc.unc.edu/measure/ publications/sr-09-52

[22] Devaney B, Moffitt R. Dietary effects of the food stamp program. Am J Agric Econom 1991; 73: 202-11. http://dx.doi.org/10.2307/1242896

[23] Mani-Murage E, Holding P, Fotso JC, Ezeh A, Madise N, et al. Food security and nutritional outcomes among urban poor orphans in Nairobi, Kenya. J Urban Health 2011; 88: 282-97. http://dx.doi.org/10.1007/s11524-010-9491-z

[24] Bolanle MF, Fidelis ON, Adebiyi OO. Prevalence, types and demographic features of child labour among school children in Nigeria. BMC Int Health Human Rights 2005; 5: 2. http://dx.doi.org/10.1186/1472-698X-5-2

[25] Daly G, Dipayan B, Bal PD. Food Security And Child Work In Rural India. wfp.org/stellent/groups/public/documents/ena/ wfp035252.pdf Retrieved 25/7/13

[26] Hadley C, Lindstrom D, Tessema F, Belachew T. Gender bias in the food insecurity experience of Ethiopian adolescents. Soc Sci Med 2008; 66: 427-38. 